\title{
Expresión de Tuftelina en Gérmenes Dentales Humanos
}

\author{
Expression of Tuftelin in Human Dental Germs
} Campos-Navarro, Paloma María ${ }^{1}$; Guerrero-Barrera, Alma Lilian ${ }^{1}$; Avelar-González, Francisco Javier² ${ }^{2}$ Navarro-Rincón-
Gallardo, María Esther ${ }^{3}$; Mariel-Murga, Humberto ${ }^{3}$; Mariel-Cárdenas, Jairo ${ }^{3}$ \& Gutiérrez-Cantú, Francisco Javier ${ }^{4}$

CAMPOS-NAVARRO, P. M.; GUERRERO-BARRERA, A. L.; AVELAR-GONZÁLEZ, F. J.; NAVARRO-RINCÓN-GALLARDO, M. E.; MARIEL-MURGA, H.; MARIEL-CÁRDENAS, J. \& GUTIÉRREZ-CANTÚ, F. J. Expresión de tuftelina en gérmenes dentales humanos. Int. J. Morphol., 35(1):293-298, 2017.

RESUMEN: La tuftelina es una proteína secretada en la matriz adamantina en desarrollo durante la formación del esmalte. Su función continúa sin esclarecerse, aunque se presume que juega un papel importante en la biomineralización de esmalte y dentina, así como en el desarrollo del órgano dental. Con el presente estudio se identificó su localización en las diferentes estructuras de gérmenes dentales de fetos humanos, conforme a los resultados se observó su expresión en el estadio pre-secretor observándose en el citoplasma de los ameloblastos, retículo estrellado, papila dental, así como en el estrato intermedio; en el secretor se identificó principalmente en la unión amelodentinaria, y en la superficie externa del esmalte, observando una marcada expresión de la proteína en la porción basal del proceso odontoblástico, pero no en la matriz extracelular de la dentina. De acuerdo a los resultados obtenidos se puede considerar que su expresión se presenta tanto en la amelogénesis, como en la odontogénesis en tejidos sin mineralizar,

PALABRAS CLAVE: tuftelina; inmunohistoquímica; amelogénesis.

\section{INTRODUCCIÓN}

El esmalte dental es el tejido más duro y mineralizado del cuerpo humano. Su formación se caracteriza por un proceso de desarrollo intenso y organizado (Fincham et al., 1999), que se forma químicamente por matriz inorgánica, (95\%), agua (3-5\%) y por matriz orgánica (1-2\%) (Gutiérrez-Cantú et al., 2011, 2014). El proceso de amelogénesis involucra a los ameloblastos, los cuales, secretan proteínas de la matriz orgánica que incluyen amelogeninas, ameloblastinas, enamelinas y tuftelinas, las cuales son capaces de guiar la formación de los prismas del esmalte, con la previa producción de dentina (Simmer \& Hu, 2002; Lacruz et al., 2010; Jeremias et al., 2013; Tariq et al., 2014). La mayor parte de los estudios realizados previamente se han realizado en modelos animales. La tuftelina se encuentra catalogada dentro del grupo de las proteínas noamelogeninas, siendo la primera proteína de ellas en ser caracterizada (Zeichner-David, 2001; Catón \& Tucker, 2009). El grupo de proteínas no-amelogeninas incluye a la enamelina, ameloblastina y tuftelina (Zeichner-David, 2001; Mihu et al., 2008, Gutiérrez-Cantú et al., 2014).
Esta es una proteína específica no-amelogenina, que originalmente fue identificada y caracterizada en el esmalte extracelular maduro y en desarrollo (Deutsch et al., 2011); se considera que juega un papel importante en la calcificación del esmalte (Deutsch et al., 1995, 1998, 2002). Es glicosilada con sitios de fosforilación de serina y treonina (Deutsch et al., 2002). Las células epiteliales la expresan en etapas tempranas de la odontogénesis (Zeichner-David et al., 1997; Deutsch et al., 1998, 2002; Leiser et al., 2007) y desempeñan un papel importante en la mineralización y organización estructural del esmalte pudiendo ser importante en la nucleación de los cristales adamantinos (Deutsch et al., 2002).

La expresión de esta proteína se ha observado en numerosos tipos de tejidos en diferentes orígenes embriológicos (mesenquimal, epitelial y neuronal) (Mao et al., 2001; Deutsch et al., 2002; Shay et al., 2009), tejidos mineralizados normales y con presencia de células cáncerosas (Mao et al., 2001; Deutsch et al., 2002; 2011; Leiser et al., 2007). Su

\footnotetext{
${ }^{1}$ Laboratorio de Biología Celular y Tisular, Departamento de Morfología. Universidad Autónoma de Aguascalientes, Aguascalientes, México.

${ }^{2}$ Laboratorio de Ciencias Ambientales, Departamento de Fisiología y Farmacología. Universidad Autónoma de Aguascalientes, Aguascalientes, México.

${ }^{3}$ Laboratorio de Disecciones, Departamento de Morfología. Universidad Autónoma de San Luis Potosí, San Luis Potosí, México.

${ }^{4}$ Laboratorio de Histología, Departamento de Morfología. Universidad Autónoma de San Luis Potosí, San Luis Potosí, México.
} 
peso molecular es de $44 \mathrm{KDa}$ con un punto isoeléctrico de 5,7 (Shay et al., 2009), y se considera una proteína no específica del esmalte (Deutsch et al., 2002). Parece restringirse al área de la unión amelodentinaria (DEJ) y aparece como producto de los ameloblastos jóvenes y pre-odontoblastos. Debido a su ubicación restringida se ha propuesto que juega un papel en la inducción y el inicio de la mineralización así como un material de unión que une al esmalte y la dentina (Avery, 2011). Se localiza principalmente dentro del citoplasma de la célula; se acumula en regiones citoplasmáticas definidas, no así en el aparato de Golgi y/o gránulos de secreción, de los ameloblastos. (Luo et al., 2004). Se ha identificado su expresión dentro de los procesos de los odontoblastos durante las primeras etapas de desarrollo de los órganos dentales y en la porción del esmalte adyacente a la DEJ en etapas posteriores (Simmer \& Fincham, 1995). Esta proteína, al igual que la amelogenina, se ha considerado de auto-montaje, así como se ha sugerido su relación en el desarrollo y mineralización del esmalte, pero su función específica aun es desconocida (Paine et al., 1998). Se cree que, junto con la enamelina, tienen una función primaria en la nucleación de los cristales del esmalte (Termine et al., 1980; Diekwisch et al., 1997) y se expresa en varios tejidos no mineralizados, lo cual sugiere que tiene una función universal y/o un papel multifuncional (Deutsch et al., 2002; Leiser, et al., 2007; Jeremias, et al., 2013) en el proceso de desarrollo que se activa durante la organogénesis (Leiser, et al., 2007). Deben distinguirse de las proteínas tuft, que son proteínas extremadamente insolubles o fragmentos de proteínas secretadas durante la amelogenesis temprana, que quedan en la matriz calcificada durante la maduración del esmalte y se identifican en los penachos, que son los haces sinuosos de material orgánico que pueden ser reconocidos histológicamente en la DEJ (Deutsch et al., 1995).

Debido a la importancia que tiene la tuftelina en el desarrollo y mineralización del órgano dental, el objetivo del presente estudio fue determinar su localización en las diferentes estructuras de gérmenes dentales en fetos humanos.

\section{MATERIAL Y MÉTODO}

Consideraciones éticas. El Comité de Educación, Investigación y Ética del Hospital General de Zacatecas, México; es la institución que realizó la donación de los fetos humanos, y también suministró los permisos para su uso en esta investigación.

Obtención de especímenes. Se analizaron cinco fetos de entre 14 y 22 semanas de gestación; se realizó una valoración macroscópica a cada espécimen, con lo que se descartó cual- quier malformación, para posteriormente hacer la disección de los fetos, y obtener cinco maxilares superiores y cinco inferiores, cada uno dividido en derecho e izquierdo, con lo que se obtuvieron 20 hemimaxilas, las cuales se fijaron en formalina neutra al $10 \%$.

\section{Preparación de especímenes}

Immunohistoquímica. Las hemimaxilas se colocaron en una solución de descalcificación de ácido etilendiaminotetraacético al $10 \%$ (EDTA) durante 15 días, se tomaron radiografías periapicales para evaluar el progreso de la decalcificación, una vez descalcificados, los especímenes se lavaron en PBS al $1 \%$ durante 30 minutos y se embebieron en parafina. Se realizaron cortes seriados de $5 \mathrm{~mm}$ de grosor realizándose el desenmascaramiento de epítopes en una solución de citrato de sodio al $0.01 \mathrm{M}$ con un $\mathrm{pH}$ de 6.0 por lapsos de 25, 10, 8, 5 y 5 segundos en un horno de microondas con intervalos de 2 minutos entre cada lapso. Se bloquearon las peroxidasas endógenas y se aplicó un anticuerpo policlonal anti-tuftelina contra conejo (Molecular Probes) diluido 1:100, como anticuerpo secundario se utilizó el sistema Dako LSAB HRP (Dako, Glostrup, Denmark), se contratiñó con hematoxilina (Allen et al., 1994). Las imágenes se obtuvieron con un microscopio Leika DM 1000 equipado con el analizador de Leica Acquire. El cálculo del tamaño de la muestra se obtuvo de acuerdo a la fórmula de Cummins y Hulley (Hulley \& Cummins, 1988). Obteniendo un total de 20 muestras para analizar.

\section{RESULTADOS}

Utilizando un anticuerpo policlonal $\operatorname{IgG}$ anti-tuftelina contra conejo, se detectaron patrones significativos de tinción en el esmalte en desarrollo de gérmenes dentales de fetos humanos de entre 14 y 22 semanas de gestación, tanto en el estadio pre-secretor como en el secretor.

Localización de la tuftelina en el estadio pre-secretor. Las microfotografías de los controles como de la inmunotinción de este estadio fueron obtenidas germenes dentales en estadios de campana temprana. Las figuras 1a y 1c se tomaron a $40 \mathrm{x}$ y la $1 \mathrm{~b}$ y $1 \mathrm{~d}$ a $100 \mathrm{x}$. Los controles se tiñeron con hematoxilina-eosina logrando observarse los ameloblastos presecretores (A), el retículo estrellado (SR), la papila dental (P) y el estrato intermedio (SI) (Fig. 1a y 1b).

Los resultados de la inmunotinción con el anticuerpo para tuftelina en el estadio pre-secretor muestra una reacción casi homogénea intensa en todos los componentes del germen dental, siendo un poco más intensa en la porción basal 
a

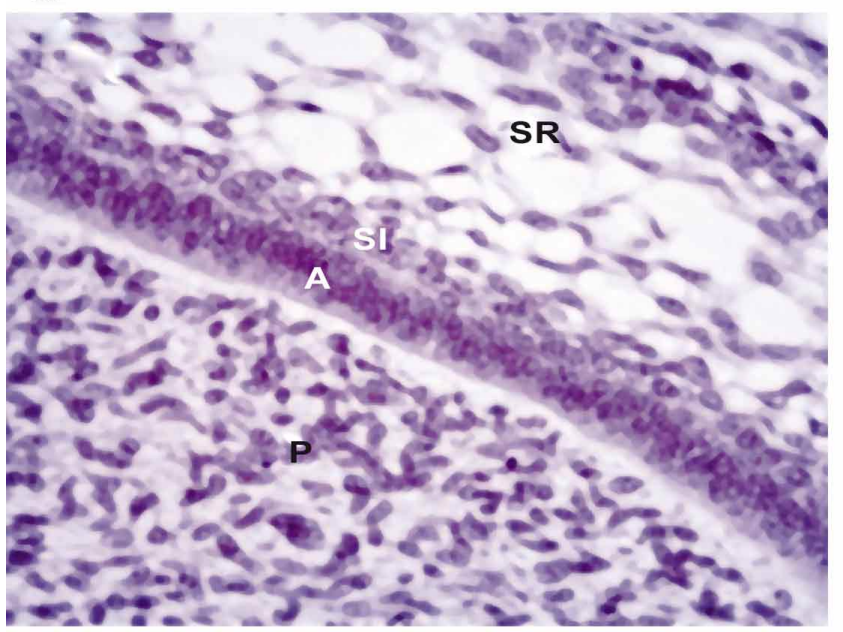

C

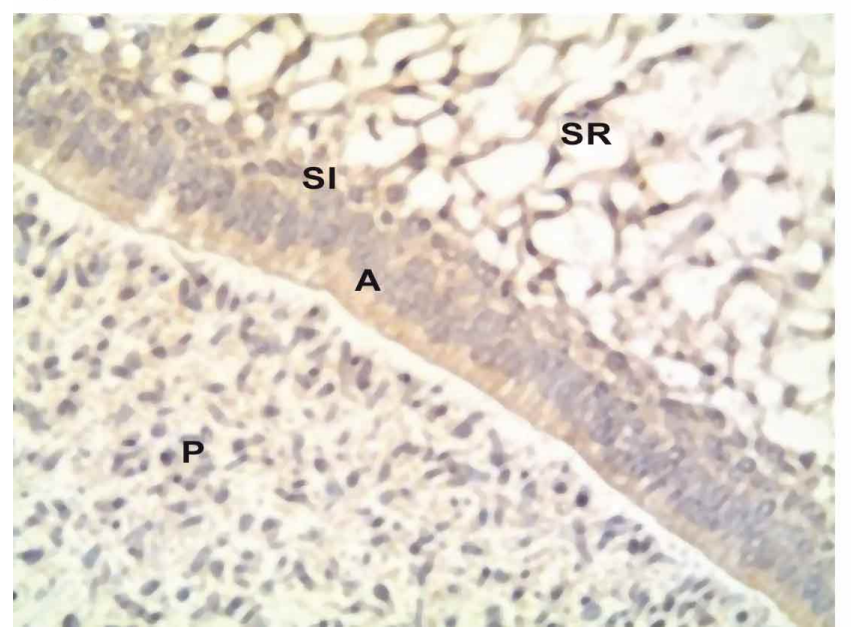

b

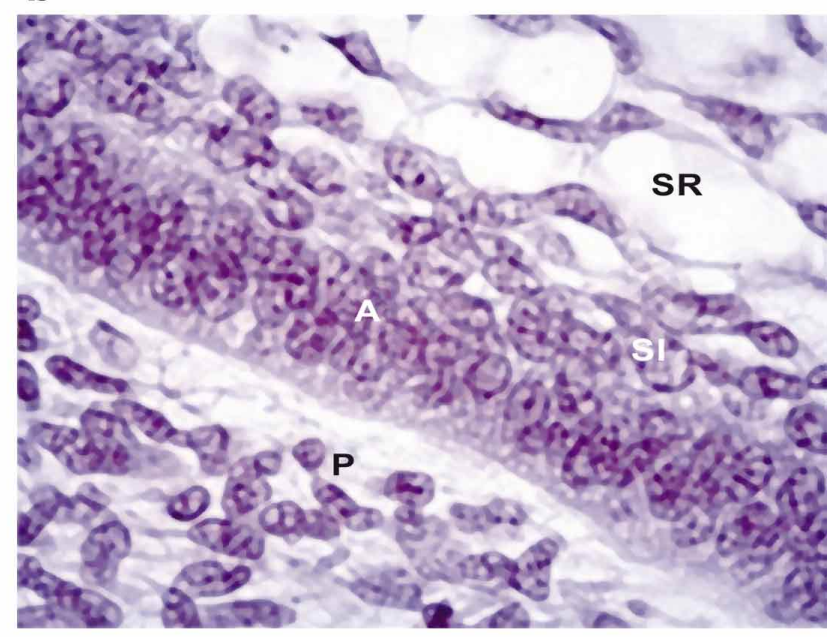

d

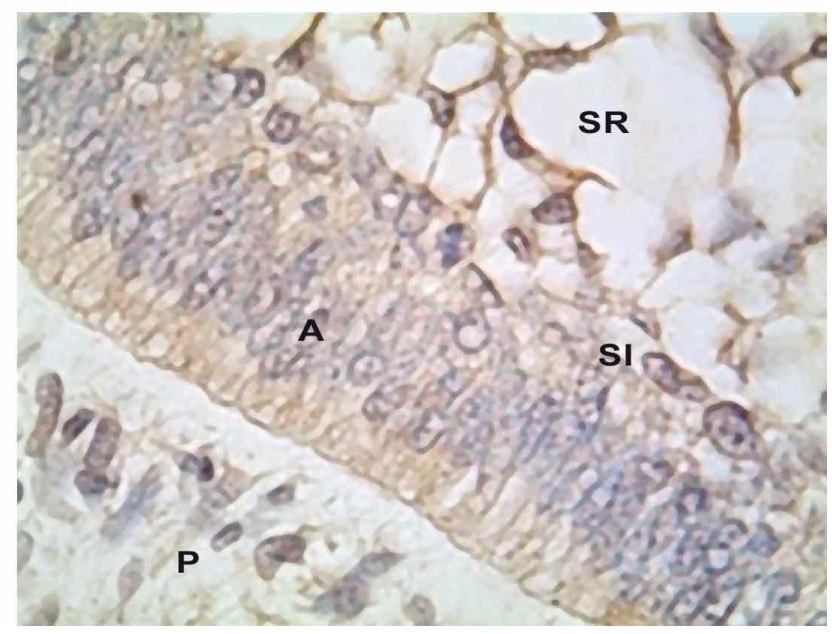

Fig. 1. Reconocimiento específico de tuftelina en fetos humanos en el estadio presecretor del germen dental. Imágenes a 40x (a y c) y a 100x (b y d). Imágenes a 40x (a y c) y a 100x (b y d). Las microfotografías muestran: Controles Tinción H-E (a y b). En el estadio presecretor se encuentra en todo el citoplasma de los ameloblastos (A), en la papila dental (P), en el retículo estrellado (SR) y en el estrato intermedio (SI) (c y d).

del citoplasma de los ameloblastos, disminuye hacia la región apical, el retículo estrellado, la papila dental, así como en el estrato intermedio (Fig. 1c y 1d).

Localización de la tuftelina en el estadio secretor. Las microfotografías de este estadio fueron tomadas de un germen dental en estadio de campaña tardío, periodo en el que ya hay producción tanto de esmalte como de dentina. Las Figuras 1a, 1c y 1e se encuentran a 40x y las $1 \mathrm{~b}, 1 \mathrm{~d}$ y $1 \mathrm{f}$ a $100 x$.

Las Figuras 2a y 2c pertenecen a la región cúspidea de un molar, en el cual ya se observa una porción de esmalte y dentina mineralizados $y$, las figuras $2 \mathrm{~b}$ y $2 \mathrm{~d}$ corresponden a la región hacia cervical, en donde apenas comienza la secreción de esmalte.
El control de la región cúspidea del estadio secretor teñido con Hematoxilina-eosina, muestra el retículo estrellado, esmalte, odontoblastos, DEJ, la dentina del manto y predentina (Fig. 2a); mientras que en el control de la región cervical solo se observan el esmalte, la dentina del manto y los odontoblastos (Fig. 2b).

Con la inmunotinción en la región cúspidea del estadio secretor se identifica la presencia de la tuftelina principalmente en el esmalte y en la unión amelodentinaria, notando que su distribución en el espesor del esmalte no es homogénea, observándose una fina línea concentrada en la unión amelodentinaria y en el esmalte más superficial (Fig. 2c), entretanto en la región cervical la reacción primordial se percibe en la superficie externa del esmalte (Fig. 2d); hacia el área de 
a

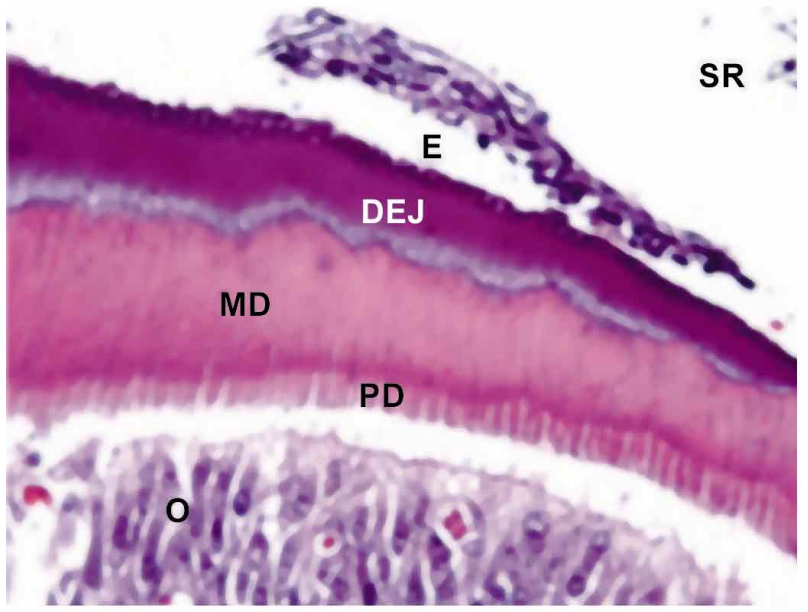

C

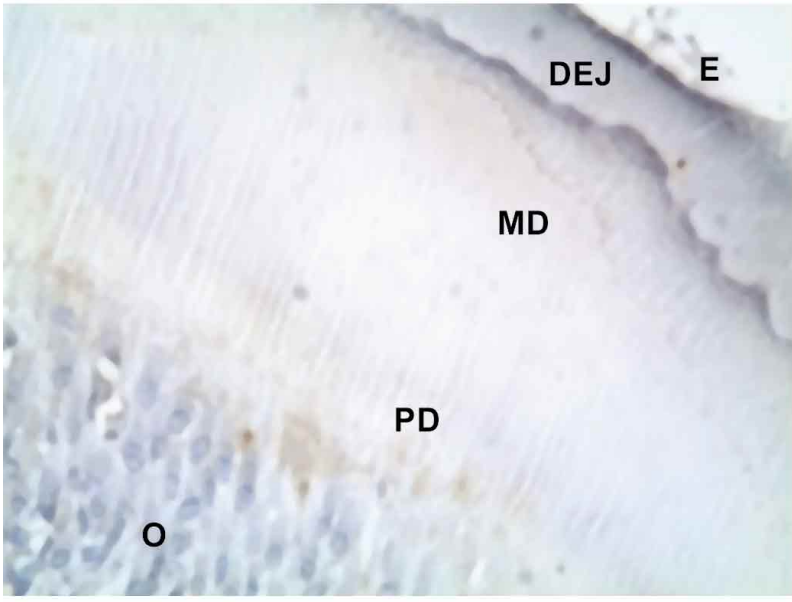

e

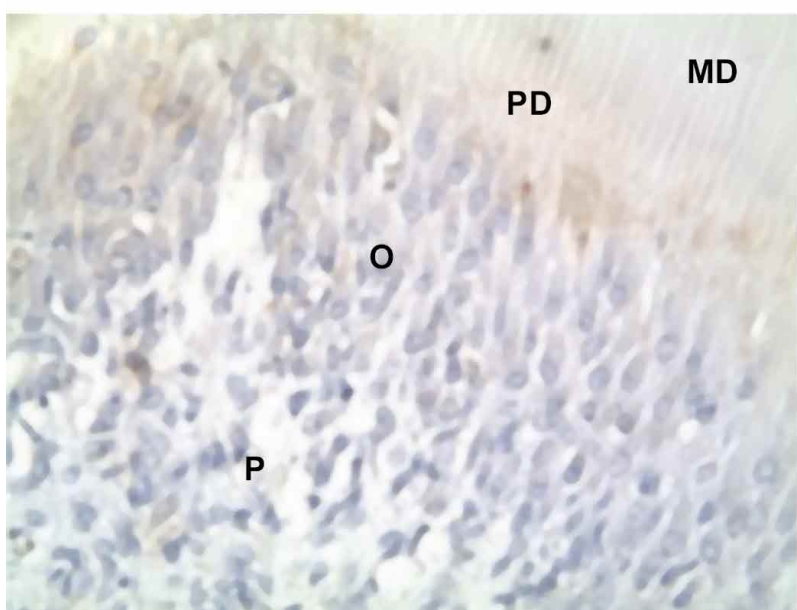

b

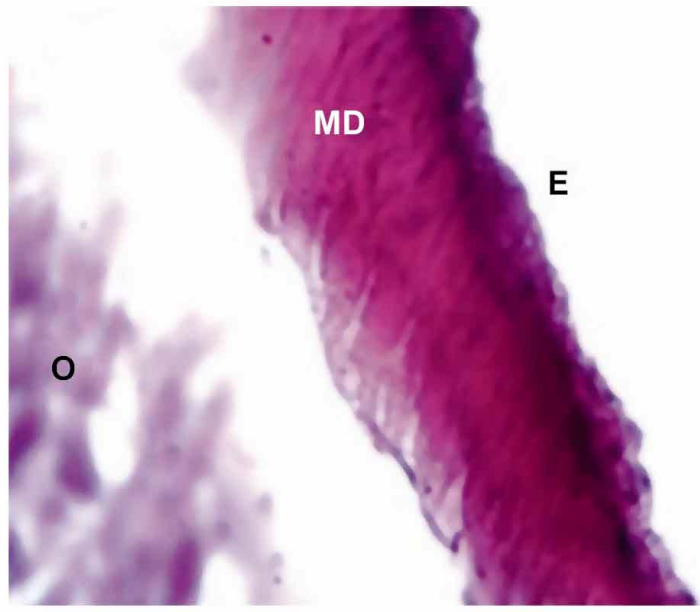

d

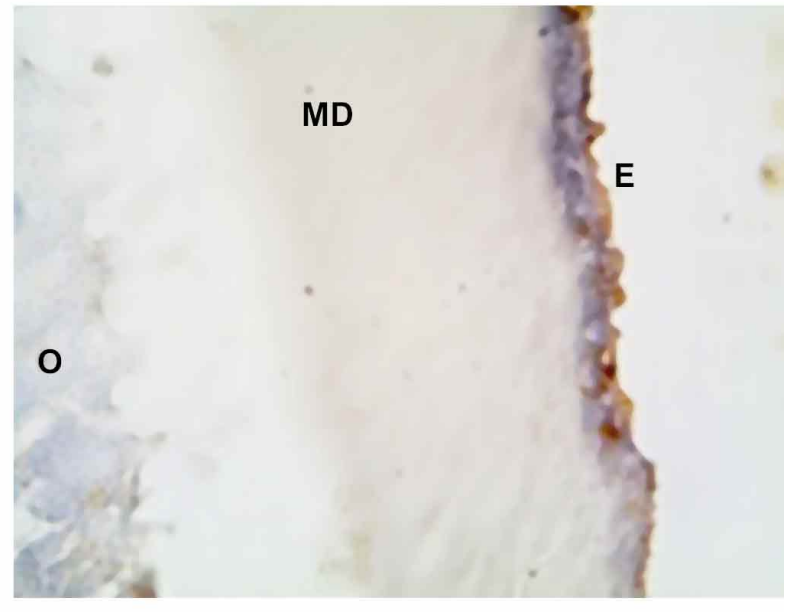

f

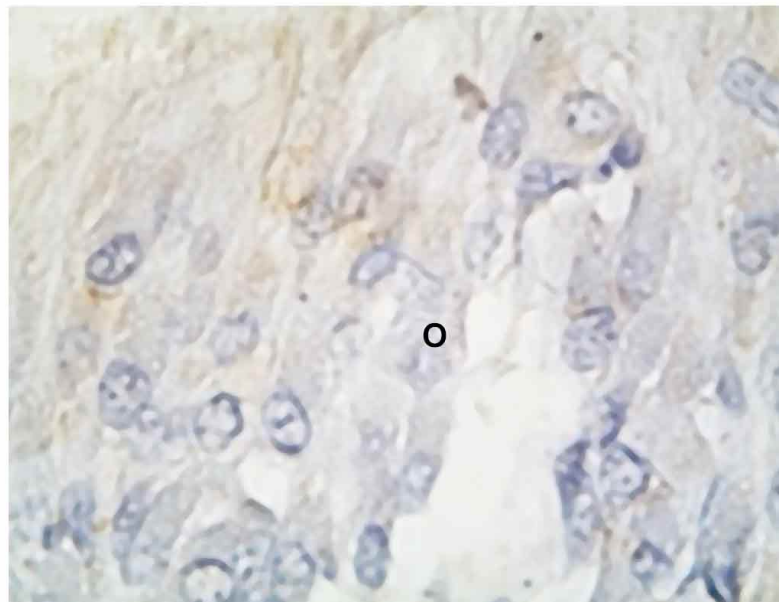

Fig. 2. Reconocimiento específico de tuftelina en fetos humanos en el estadio secretor del germen dental. Imágenes de la izquierda a 40x y de la derecha a 100x. Controles Tinción H-E (a y b). Inmunotinción de tuftelina (c, d, e y f). En el estadio secretor se encuentra más concentrada en la unión amelodentinaria (DEJ) y en el esmalte más superficial (E) (c y d); se observa una reacción menos intensa en predentina (PD) y en los odontoblastos secretores (O) y vestigios en dentina del manto (DM) y predentina, así como en el esmalte y dentina mineralizados (e y f); en esta etapa no hay expresión de la proteína en papila (P) (e). 
predentina (Fig. 2c y 2e) y en la parte basal de los odontoblastos secretores la reacción disminuye (Fig. 2e y 2f) y, en la dentina del manto (Fig. 2c y 2d) así como en el esmalte y dentina mineralizados solo se pueden distinguir vestigios (Fig. 2c). En esta etapa no se observa presencia en la papila (Fig. 2e).

\section{DISCUSIÓN}

Estudios previos realizados en modelos animales indican que la tuftelina es sintetizada por los ameloblastos durante las etapas tempranas del desarrollo del esmalte, y, continúa presente en el esmalte extracelular durante su desarrollo y mineralización (Deutsch et al., 1995; 1998; 2002; MacDougall et al., 1998; Zeichner-David, 2001; Mao et al., 2001; Satchell et al., 2002) En esta investigación se analizaron maxilares superiores e inferiores de fetos humanos; se corroboró que la secreción de la proteína es sintetizada desde etapas tempranas del desarrollo del órgano dental y en el esmalte en desarrollo, no así en el esmalte extracelular mineralizado.

Aunque esta proteína es importante en el desarrollo y mineralización del diente, existen muy pocos conocimientos sobre ella en dientes humanos. (Deutsch et al., 1998; Simmer \& Hu et al., 2002). Esta proteína no es específica del órgano dental, ya que se ha encontrado que se expresa en otros tejidos incluyendo riñón, hígado, pulmón y testículos, debido a esto se cree que tiene una función fisiológica más general, que pudiera ser el desarrollo de éstos tejidos, pero aún no ha sido determinada (MacDougall et al., 1998; Satchell et al., 2002).

Previamente se ha referido que la expresión de tuftelina comienza durante el estadio pre-secretor (Mao, et al., 2001), antes de la mineralización, cuando los ameloblastos pre-secretores, pre-odontoblastos y células mesenquimatosas de la papila están presentes (Deutsch $e t$ $a l, 1998)$. Nuestros resultados concuerdan con los autores ya que se identifico la mayor expresión de la proteína previo al inicio de la mineralización.

Se ha comprobado que el periodo pre-secretor es el periodo en el que la tuftelina tiene mayor expresión, observándose una reacción homogénea en el citoplasma de los ameloblastos (Luo et al., 2004), particularmente en la región secretora de la célula (el proceso de Tomes) (Deutsch et al, 1998), el retículo estrellado y la papila dental. En nuestro estudio se corroboro la expresión de tuftelina en las estructuras mencionadas, asi como se logro identificar presencia de la proteína en odontoblastos, tal vez debido que esta juega un papel importante en la inducción de la formacion de la primera dentina o de manto, la cual estimu- la la producción de la matriz del esmalte.

Durante la amelogenesis la tuftelina se expresa en el polo apical del odontoblasto, y se ha especulado que la tuftelina podría haberse producido originalmente en los odontoblastos, asi como posteriormente secretarse a través de los procesos de los odontoblastos a la matriz del esmalte recién formado para apoyar la nucleación de los cristales, o la tuftelina pudiera ser secretada originalmente por los ameloblastos, y subsecuentemente traslocarse a la porción mesenquimal del órgano dental (Diekwisch et al., 1997). Los resultados de este estudio difieren en la localizacion en el odontoblasto, ya que se observa una marcada expresion en la porción basal y más atenuada en la apical lo cual indica la producción de esta proteína por el odontoblasto, además no se identificó marcaje en la matriz extracelular de la dentina.

Deutsch et al. (1998) refiere que la expresión de la tuftelina se da en los ameloblastos, especialmente en el proceso de Tomes y en la matriz extracelular del esmalte en desarrollo subyacente, y que aparentemente la proteína no se encuentra presente en odontoblastos y en la matriz extracelular de la dentina, también reacciona con el esmalte maduro de humanos y bovino. En los resultados de esta investigación existe una diferencia con ellos, ya que no obtuvimos reacción en la matriz del esmalte, ni en el esmalte maduro, pero sí en los odontoblastos.

Diversos autores han encontrado que durante la etapa secretora la localización de la tuftelina, en ejemplares animales, se identifica principalmente en la DEJ y en la matriz del esmalte en desarrollo, observándose como una fina línea paralela a la DEJ y al esmalte recién secretado, encontrando altas concentraciones de proteina en la DEJ durante el desarrollo temprano del esmalte (Simmer \& Fincham., 1995; Diekwisch et al.,1997; Zeichner-David et al, 1997; Mao et al., 2001; Satchell et al., 2002), estos acontecimientos coinciden con nuestros resultados realizados en gérmenes de fetos humanos. El que la tuftelina se encuentre en proximidad de la DEJ puede indicar su relacion en la nucleación de los cristales del esmalte (Satchell et al., 2002; Luo et al., 2004). De acuerdo a los resultados obtenidos es posible suponer que la tuftelina no solamente se expresa durante el proceso de amelogenesis, sino en el de odontogénesis, pero en tejidos no mineralizados (MacDougall et al., 1998; Luo et al., 2004), por lo que aunque el rol de la tuftelina en el desarrollo del esmalte todavía no se ha clarificado, lo cual puede indicar que esta proteína juega un papel importante en la biomineralización de esmalte y dentina, con lo anterior se deduce que una déficit o ausencia de tuftelina derivara en un transtorno de mineraliacion de esmalte y dentina de manto. 
AGRADECIMIENTOS. Paloma María Campos Navarro fue apoyada con la beca CONACYT no. 415360. Agradecemos a la Bióloga Adriana Cecilia Moreno Flores del laboratorio de Biología Celular de la Universidad Autónoma de Aguascalientes y al ISC. Edgardo Martínez Martin Del Campo, catedrático de la Facultad de Estomatología de la UASLP, por su apoyo técnico.

CAMPOS-NAVARRO, P. M.; GUERRERO-BARRERA, A. L.; AVELAR-GONZÁLEZ, F. J.; NAVARRO-RINCÓN-GALLARDO, M. E.; MARIEL-MURGA, H.; MARIEL-CÁRDENAS, J. \& GUTIÉRREZ-CANTÚ, F. J. Expression of tuftelin in human dental germs. Int. J. Morphol., 35(1):293-298, 2017.

SUMMARY: The tuftelin is a secreted protein in the adamantine matrix in developing during the enamel formation. Its function continues unclarified, although it plays a role in the biomineralization of the dental organ. With the present studio the location was identified in the different structures of dental germs from human fetuses, according to the results it was observed the expression in the pre-secretor stage being observed in the cytoplasm of ameloblasts, stellate reticulum, dental papilla, also in the intermediate stratum; in the secretor it was mainly identified in the amelodentinal junction and in the outer surface of enamel, observing a marked expression of the protein in the basal portion of the odontoblastic process, but not in the extracellular matrix of the dentine. According to the results obtained it can be considered that its expression occurs in both amelogenesis and odontegenesis in unmineralized tissues.

KEY WORDS: Tuftelin; Immunohistochemistry; Amelogenesis.

\section{REFERENCIAS BIBLIOGRÁFICAS}

Avery, J. K. Oral Development and Histology. $3^{\text {rd }}$ ed. Stuttgart, Thieme, 2011.

Catón, J. \& Tucker, A. S. Current knowledge of tooth development: patterning and mineralization of the murine dentition. J. Anat., 214(4):502-15, 2009.

Deutsch, D.; Leiser, Y.; Shay, B.; Fermon, E.; Taylor, A.; Rosenfeld E., Dafni, L.; Charuvi, K.; Cohen, Y.; Haze, A.; Fuks, A. \& Mao, Z. The human tuftelin gene and the expression of tuftelin in mineralizing and nonmineralizing tissues. Connect. Tissue Res., 43(2-3):425-34, 2002.

Deutsch, D.; Silverstein, N.; Shilo, D.; Lecht, S.; Lazarovici, P. \& Blumenfeld, A. Biphasic influence of hypoxia on tuftelin expression in mouse mesenchymal C3H10T1/2 stem cells. Eur. J. Oral Sci., 119 Suppl. 1:55-61, 2011.

Deutsch, D.; Palmon, A.; Dafni, L.; Catalano-Sherman, J.; Young, M. F. \& Fisher, L. W. The enamelin (tuftelin) gene. Int. J. Dev. Biol., 39(1):135-43, 1995.

Deutsch, D.; Palmon, A.; Dafni, L.; Mao, Z.; Leytin, V.; Young, M. \& Fisher, L. W. Tuftelin--aspects of protein and gene structure. Eur. J. Oral Sci., 106 Suppl. 1:315-23, 1998.

Diekwisch, T. G.; Ware, J.; Fincham, A. G. \& Zeichner-David, M. Immunohistochemical similarities and differences between amelogenin and tuftelin gene products during tooth development. J. Histochem. Cytochem., 45(6):859-66, 1997.

Fincham, A. G.; Moradian-Oldak, J. \& Simmer, J. P. The structural biology of the developing dental enamel matrix. J. Struct. Biol., 126(3):270-99, 1999.

Gutiérrez-Cantú, F. J.; Feria-Velasco, A.; Palacios-Arenas, L. N.; AlvaradoEstrada, K. N.; Avelar-González, F. J.; Flores-Reyes, H.; Mariel-Cárdenas, J., \& Guerrero-Barrera, A. L. Amelogenin and enamelysin localization in human dental germs. In Vitro Cell. Dev. Biol. Anim., 47(5-6):355-60, 2011. Gutiérrez-Cantú, F. J.; Cárdenas, J. M.; Rodríguez, R. O.; Romo Ramírez, G.
F.; Sánchez Méraz, W.; Murga, H. M. \& Leal Tobias, L. A. Expression of Mmp-20 in dental germs of human fetus. Int. J. Morphol., 32(4):1261-5, 2014.

Jeremias, F.; Koruyucu, M.; Küchler, E. C.; Bayram, M.; Tuna, E. B.; Deeley, K.; Pierri, R. A.; Souza, J. F.; Fragelli, C. M.; Paschoal, M. A.; Gencay, K.; Seymen, F.; Caminaga, R. M.; dos Santos-Pinto, L. \& Vieira, A. R. Genes expressed in dental enamel development are associated with molar-incisor hypomineralization. Arch. Oral Biol., 58(10):1434-42, 2013.

Hulley, E. B. \& Cummings, S. R. Designing Clinical Researc: An Epidemiologic Approach. Baltimore, Williams and Wilkins Co., 1988.

Lacruz, R. S.; Nanci, A.; Kurtz, I.; Wright, J. T. \& Paine, M. L. Regulation of pH during amelogenesis. Calcif. Tissue Int., 86(2):91-103, 2010.

Leiser, Y.; Blumenfeld, A.; Haze, A.; Dafni, L.; Taylor, A. L.; Rosenfeld, E.; Fermon, E.; Gruenbaum-Cohen, Y.; Shay, B. \& Deutsch, D. Localization, quantification, and characterization of tuftelin in soft tissues. Anat. Rec. (Hoboken), 290(5):449-54, 2007.

Luo, W.; Wen, X.; Wang, H. J.; MacDougall, M.; Snead, M. L. \& Paine, M. L. In vivo overexpression of tuftelin in the enamel organic matrix. Cells Tissues Organs, 177(4):212-20, 2004.

MacDougall, M.; Simmons, D.; Dodds, A.; Knight, C.; Luan, X.; ZeichnerDavid, M.; Zhang, C.; Ryu, O. H.; Qian, Q.; Simmer, J. P. \& Hu, C. C. Cloning, characterization, and tissue expression pattern of mouse tuftelin cDNA. J. Dent. Res., 77(12):1970-8, 1998.

Mao, Z.; Shay, B.; Hekmati, M.; Fermon, E.; Taylor, A.; Dafni, L.; Heikinheimo, K.; Lustmann, J.; Fisher, L. W.; Young, M. F. \& Deutsch, D. The human tuftelin gene: cloning and characterization. Gene, 279(2):181-96, 2001.

Mihu, C. M.; Dudea, D.; Melincovici, C. \& Bocs a, B. Tooth enamel, the result of the relationship between matrix proteins and hydroxyapatite crystals. Appl. Med. Inform., 23(3-4):68-72, 2008.

Paine, M. L.; Krebsbach, P. H.; Chen, L. S.; Paine, C. T.; Yamada, Y.; Deutsch, D. \& Snead, M. L. Protein-to-protein interactions: criteria defining the assembly of the enamel organic matrix. J. Dent. Res., 77(3):496-502, 1998.

Satchell, P. G.; Anderton, X.; Ryu, O. H.; Luan, X.; Ortega, A. J.; Opamen, R.; Berman, B. J.; Witherspoon, D. E.; Gutmann, J. L.; Yamane, A.; ZeichnerDavid, M.; Simmer, J. P.; Shuler, C. F. \& Diekwisch, T. G. Conservation and variation in enamel protein distribution during vertebrate tooth development. J. Exp. Zool. Part A Ecol. Genet.Physiol., 294(2):91-106, 2002.

Shay, B.; Gruenbaum-Cohen, Y.; Tucker, A. S.; Taylor, A. L.; Rosenfeld, E.; Haze, A.; Dafni, L.; Leiser, Y.; Fermon, E.; Danieli, T.; Blumenfeld, A. \& Deutsch D. High yield expression of biologically active recombinant full length human tuftelin protein in baculovirus-infected insect cells. Protein Expr. Purif., 68(1):90-8, 2009.

Simmer, J. P. \& Fincham, A. G. Molecular mechanisms of dental enamel formation. Crit. Rev. Oral Biol. Med., 6(2):84-108, 1995.

Simmer, J. P. \& Hu, J. C. Expression, structure, and function of enamel proteinases. Connect. Tissue Res., 43(2-3):441-9, 2002.

Tariq, A.; Alam Ansari, M.; Owais Ismail, M. \& Memon, Z. Association of the use of bacterial cell wall synthesis Inhibitor drugs in early childhood with the Developmental Defects of Enamel. Pak. J. Med. Sci., 30(2):393-7, 2014.

Zeichner-David, M.; Vo, H.; Tan, H.; Diekwisch, T.; Berman, B.; Thiemann, F.; Alcocer, M. D.; Hsu, P.; Wang, T.; Eyna, J.; Caton, J.; Slavkin, H. C. \& MacDougall, M. Timing of the expression of enamel gene products during mouse tooth development. Int. J. Dev. Biol., 41(1):27-38, 1997.

Zeichner-David, M. Is there more to enamel matrix proteins than biomineralization? Matrix Biol., 20(5-6):307-16, 2001.

\section{Dirección para correspondencia:}

Dr. Francisco Javier Gutiérrez Cantú

Profesor Investigador

Facultad de Estomatología U.A.S.L.P.

Av. Manuel Nava 2, San Luis Potosí, S.L.P.

Código Postal: 78290

MÉXICO

Email: pacogtz@uaslp.mx
Recibido : 31-08-2016

Aceptado: 22-12-2016 